\title{
In-vitro Evaluation of Chitosan - Hydroxyapatite Nanocomposite Scaffolds as Bone Substitutes with Antibiofilm Properties
}

\author{
Anuj Nishanth Lipton ${ }^{1 *}$ (D) Aifa Fathima ${ }^{2}$ (D) and S.G.P. Vincent ${ }^{2 *}$ (D) \\ ${ }^{1}$ Curtin Malaysia Research Institute, Curtin University, CDT 250, 98009 Miri, Sarawak Malaysia. \\ ${ }^{2}$ Centre for Marine Science \& Technology, Manonmaniam Sundaranar University, \\ Rajakkamangalam- 629 502, Tamil Nadu, India.
}

\begin{abstract}
An opaque, white chitosan/ Hydroxyapatite nanocomposite was prepared by a simple blend method. Morphology, pore size and dispersion of nano-hydroxyapatite in chitosan matrix were visualized using SEM images. The FTIR and SEM with EDX analysis confirmed the bony apatite layer was formed on the outside of the composite. Porosity measurements and water uptake studies of the nanocomposite were evaluated which revealed the maximum porosity of $80 \%$ to $92 \%$ in the chitosan: hydroxyapatite nanocomposite at the ratio of 20:80. The results also showed that water absorption ability was inversely proportional to the hydroxyapatite present in the nanocomposite. The porosity of prepared nanocomposite was corresponding to the cancellous bone porosity of $50 \%$ to $90 \%$ suggesting possible applications in bone transplantation. The nanocomposite exhibited antibacterial activity towards the tested Gram-negative and Gram-positive species of bacteria and reduced the bacterial adhesion in biofilm formation.
\end{abstract}

Keywords: Chitosan, Hydroxyapatite, Nanocomposite, Bone implant, Antibiofilm properties

*Correspondence: anujnish99@gmail.com; prakash@msuniv.ac.in

(Received: May 19, 2021; accepted: July 24, 2021)

Citation: Lipton AN, Fathima A, Vincent SGP. In-vitro Evaluation of Chitosan - Hydroxyapatite Nanocomposite Scaffolds as Bone Substitutes with Antibiofilm Properties. J Pure Appl Microbiol. 2021;15(3):1455-1471. doi: 10.22207/JPAM.15.3.39

(C) The Author(s) 2021. Open Access. This article is distributed under the terms of the Creative Commons Attribution 4.0 International License which permits unrestricted use, sharing, distribution, and reproduction in any medium, provided you give appropriate credit to the original author(s) and the source, provide a link to the Creative Commons license, and indicate if changes were made. 


\section{INTRODUCTION}

Bone substitutes are important in the medical field and its application is increasing day by day. Artificial bone implants are very essential due to the paucity of natural bone. Thus, it is important to focus on the physico-chemical characterization, structural arrangement, and biomechanical characterization of bone substitutes, which are very important for the success of bone grafting. In many treatments, metallic implants are mostly applied, and such first-generation biomaterials are relatively successful. Although, because of its defects like stress shielding through post- healing, corrosion which causes chronic inflammation, tiredness, and detaching of the implants, they do not give the optimum therapy. This consequence leads to a second surgery to eliminate the metallic implants. It also increases the chance of the operating again which causes additional cost to the victim. To overcome this problem, the degradable polymeric implants are developed which reduces the chance of the second operation and also helps to distribute medicine to treat infections and growth factors to promote the formation of new bone.

For the development of the bioabsorbable implants, the advisable materials should have sufficient mechanical strength which induce the new bone formation by osteogenic cell at a specific site and possess osteoinductive. In orthopaedic applications, chitosan is widely used and was recommended as an alternative polymer which provides temporary mechanical support as well as the revival of bone cell ingrowth because of its good biocompatible, biodegradable, non- toxic and intrinsic wound healing features ${ }^{1-3}$. Chitosan is a linear polysaccharide that is derived from chitin. It shows specific biological properties like biodegradablity, biocompatibility, mucoadhesion, antimicrobial, anticholesterolemic and permeation enhancing effects. It also suitable to mould different structural forms like zero dimension microsphere, two-dimension membrane, threedimension pin or $\operatorname{rod}^{4}$. Hydroxyapatite (HA) is applicable in biomedical fields particularly in dental materials, hard tissue paste, bone substitute, etc. HA shows excellent biocompatibility and osteoconductivity due to its similar chemical and crystal resemblance to the mineral component of bone. On the surface of implants, the HA induces bony apatite formation ${ }^{5}$. It was found to promote bone growth when tested on dogs, indicating osteoinductive characteristic of HA.

Recently, scientists have focused on the development of HA-Chitosan (CS) composites, because it mimics both inorganic and organic phase of natural bones. CS can be easy combined with other bioactive inorganic ceramics such as HA which promotes tissue regeneration and osteoconduction. The CS/HA composites have some characteristics such as bioactivity and application like quick hardening, paste for bone repair, porous CS/HA scaffold for tissue engineering or control release of drugs. It was concluded that composite having a high amount of HA showed more brittleness to the composites. In view of this, the present study is aimed to get homogenous, porous CS/HA nanocomposites by using the blend method.

The blend method is used to make nanocomposite, which aid in the improvement of the thermal stability and extension properties of polymer blend materials in order to make high performance nanocomposites ${ }^{6-9}$. Ibrahim et al., ${ }^{10}$ proposed that from a thermodynamic standpoint, CS/HA has a significantly better energy gap, allowing it to be easily created and then interact with other biological surrounding structure. This indicates that this structure is simple to construct. The higher the contact of molecules with surrounding tissues, the lower the band gap energy. In order to interact with the active sites of chitosan, three models of hydroxyapatite were developed ${ }^{10}$. This interaction has recently become increasingly important in biology, especially since it is a very promising tool for bone substitute.

\section{MATERIALS AND METHODS}

Chitosan from shrimp shells with a degree of deacetylation $>85 \%$, was purchased from Sigma-Aldrich Co. HiMedia products such as Acetic acid (HAc, 99.8\%), Calcium nitrate tetrahydrate $\left(\mathrm{Ca}\left(\mathrm{NO}_{3}\right)_{2} 4 \mathrm{H}_{2} \mathrm{O}\right)$, diammonium hydrogen phosphate $\left(\left(\mathrm{NH}_{4}\right) \mathrm{HPO}_{2}\right)$, ethanol, hydrochloric acid $(\mathrm{HCl})$, sodium hydroxide $(\mathrm{NaOH})$, Sodium chloride $(\mathrm{NaCl})$, Sodium bicarbonate $\left(\mathrm{NaHCO}_{3}\right)$, potassium chloride $(\mathrm{KCl})$, dipotassium hydrogen phosphate $\left(\mathrm{K}_{2} \mathrm{HPO}_{4} \cdot 3 \mathrm{H}_{2} \mathrm{O}\right)$, magnesium chloride $\left(\mathrm{MgCl}_{2} \cdot 6 \mathrm{H}_{2} \mathrm{O}\right)$, calcium chloride $\left(\mathrm{CaCl}_{2}\right)$, sodium sulphate $\left(\mathrm{Na}_{2} \mathrm{SO}_{4}\right)$, tris (hydroxymethyl) 
aminomethane $\left.\left(\mathrm{CH}_{2} \mathrm{OH}\right)_{3} \mathrm{CNH}_{2}\right)$, disodium hydrogen phosphate $\left(\mathrm{Na}_{2} \mathrm{HPO}_{4}\right)$, dihydrogen potassium phosphate, crystal violet and lysozyme were used.

\section{Preparation of hydroxyapatite}

Hydroxyapatite was synthesized by the precipitation method. This was achieved by adding $60.0 \mathrm{ml}$ of $0.19 \mathrm{M} \mathrm{KH} 2 \mathrm{PO} 4$ solution slowly into 40.0 $\mathrm{ml}$ of $0.32 \mathrm{M} \mathrm{Ca}\left(\mathrm{NO}_{3}\right)_{2} \cdot 6 \mathrm{H}_{2} \mathrm{O}$ solution. The reaction was carried out at a temperature of $70^{\circ} \mathrm{C}$ at a pH values ranging between 9 and 10 and it was checked at regular intervals. The resultant solution was filtered, dried, and crushed ${ }^{11}$ to obtain the fine powder of hydroxyapatite.

Preparation of chitosan/ hydroxyapatite nanocomposite

The cylindrical Chitosan/ Hydroxyapatite rod was prepared by the blend method ${ }^{12}$ with minor modifications. The $5.0 \%$ Chitosan solution was synthesized by adding $5.0 \mathrm{~g}$ of Chitosan in $100 \mathrm{ml}$ of $2.0 \%$ acetic acid solution. Different concentrations of Hydroxyapatite (as given in Table 1) were dissolved in the Chitosan solution to obtain the Chitosan/ Hydroxyapatite mixture and were continuously mixed until the particle was well dispersed in the solution. To eliminate the air bubbles present in the solution, it was kept for $6 \mathrm{~h}$ in room temperature. The solution was poured into the cylindrical mould and the mould was soaked in $5.0 \% \mathrm{NaOH}$ solution until the solution was fully precipitated.

After precipitation of Chitosan/ Hydroxyapatite nanocomposite, it was carefully removed from the mould and was washed with distilled water until neutral $\mathrm{pH}$ was attained. Then, the gel rod was air-dried in the oven at $60.0^{\circ} \mathrm{C}$ for $24 \mathrm{~h}$ to obtain the opaque, white Chitosan/ Hydroxyapatite rod.

Table 1. The ratio of Chitosan/ Hydroxyapatite mixture

\begin{tabular}{llc}
\hline $\mathrm{CS} / \mathrm{HA}(\mathrm{w} / \mathrm{w})$ & $\mathrm{CS}(\mathrm{g})$ & $\mathrm{HA}(\mathrm{g})$ \\
\hline $100 / 5$ & 5 & 0.25 \\
$100 / 10$ & 5 & 0.50 \\
$80 / 20$ & 5 & 1.25 \\
$50 / 50$ & 5 & 5.0 \\
$20 / 80$ & 5 & 20.0 \\
\hline
\end{tabular}

\section{Physico-chemical characterization Porosity measurement}

The liquid displacement method was used to determine and calculate the porosity of nanocomposite as described by ${ }^{13}$. Primarily, the measurement of the volume of the ethanol and dry weight of the scaffold was noted. The scaffold was then soaked in the dehydrated alcohol for 5 days. The weight of the scaffold and weight of ethanol after the removal of the scaffold were noted at regular intervals. The porosity of the scaffold was evaluated by using the formula:

\section{Porosity $=$ (V1 - V3)/ (V2- V3)}

where $\mathrm{V} 1$ = initial known weight of scaffold, V2 = sum of the weights of ethanol and submerged scaffold, and $\mathrm{V} 3$ = weight of ethanol after the removal of the scaffold.

\section{Water uptake and retention ability}

Initially, the dry weight of scaffold was noted $\left(W_{\text {dry }}\right)$ and was soaked in distilled water for 5 days. During every $24 \mathrm{~h}$, the scaffold was carefully displaced on a wire mesh rack to drain excess water and the scaffold was weighed $\left(\mathrm{W}_{\mathrm{et}}\right)$ after 5 $\min$ to evaluate water uptake. Using centrifuge tube containing filter paper at the bottom, the scaffold was centrifuged at $500 \mathrm{rpm}$ for $3 \mathrm{~min}$. After centrifugation, the scaffold was weighed and was denoted as $W 1_{\text {wet }}$. Using the following formula:

$$
\begin{aligned}
& E A=[W \text { wet }-W \text { dry } / W \text { dry }] \times 100 \\
& E R=\left[W^{1} \text { wet }-W \text { dry } / W \text { dry }\right] \times 100
\end{aligned}
$$

The percentage of water uptake and retention ability of the scaffold was determined ${ }^{14}$. pH and Enzymatic degradation of the scaffold

Enzymatic degradation of the scaffold was performed using Ansari \& Amirul ${ }^{15}$ method with slight modification. The scaffold weighing $11.5 \mathrm{mg}$ was immersed in $50.0 \mathrm{ml}$ of physiological saline and stirred continuously at $37.0^{\circ} \mathrm{C}$. The $\mathrm{pH}$ of the solution was checked from day 1 to 14 at regular intervals. Phosphate Buffered Saline (PBS) solution with $\mathrm{pH} 7.4$ was used for the degradation of the nanocomposite scaffold. Initially, the dry weight of each scaffold was noted (WO). The samples were soaked in PBS solution with 500 $\mathrm{mg} / \mathrm{l}$ lysozyme at $37.0^{\circ} \mathrm{C}$ for 14 days. To ensure the constant enzymatic activity, the liquid was replaced every 3 days. The samples were removed at regular intervals and dried at $50.0^{\circ} \mathrm{C}$ for $24 \mathrm{~h}$ and noted the weight of the scaffold $\left(W_{1}\right)$. Using 
the following formula, the degradation percentage was evaluated:

W0x100

$$
\text { Degradation percentage }=(\text { WO-W1 }) /
$$

\section{Phase composition}

To find out the functional groups in Chitosan/ Hydroxyapatite nanocomposite, the Fourier Transforms Infrared (FTIR) methodology was followed. The sample was mixed with $\mathrm{KBr}$, pressed and assessed in FTIR spectroscopy within the scanning range $400-4000 \mathrm{~cm}^{-1}$. The $X$-ray diffraction with $\mathrm{CuK} \alpha$ radiation was used to analyze the crystal phase of the scaffold. Here $2 \theta$ scanning range was 10 to $60^{\circ}$ at speed of $1^{\circ} / \mathrm{min}$.

The pore size and microanalysis structure of nanocomposite were determined by Scanning Electron Microscopy with EDX. By using DSC measurements (STA 449 F3 Jupiter), the thermal stability of the nanocomposite was determined. The sample was heated up to $610.0^{\circ} \mathrm{C}$ in a dry nitrogen atmosphere from room temperature for $10 \mathrm{~min}$.

\section{Antimicrobial activity}

The antimicrobial activity of nanocomposite was determined by the standard well diffusion method on Muller Hinton (HiMedia) agar plates using different bacterial pathogenic strains. Each microbial culture containing turbidity of 0.5 McFarland was swabbed into the plates. Then, then wells were cut and labelled. Each sample was added into the appropriate well and all the plates were incubated at $37.0^{\circ} \mathrm{C}$ for $24 \mathrm{~h}$. After incubation, results were observed. The presence of a zone of inhibition was taken as the positive result which was measured by using a standard steel ruler.

Minimum inhibitory concentration (MIC) and Minimum bactericidal concentration (MBC)

For microtiter broth dilution, different concentrations of Chitosan/ Hydroxyapatite nanocomposite were prepared in $4 \mathrm{ml}$ of sterile nutrient broth (HiMedia). After labelling, $200 \mu \mathrm{l}$ of microbial culture was added in each tube. All the test tubes were incubated at $30.0^{\circ} \mathrm{C}$ for $24 \mathrm{~h}$. After incubation, optical density was measured and the lowest nanocomposite concentration that showed no growth was considered as the MIC. The effect of bacteriostatic or bactericide activity of nanocomposite was determined by spreading aliquots of each dilution on nutrient agar plates without antibiotic and all plates were incubated at $37.0^{\circ} \mathrm{C}$ for $24 \mathrm{~h}$. The lowest nanocomposite concentration that showed no colonies was denoted as the MBC.

\section{Anti-biofilm assay against bacteria}

For antibiofilm assay, overnight cultures of biofilm forming bacteria (E. coli and Streptococcus mutans) were prepared and diluted $1: 100$ in fresh media and grown for $4 \mathrm{~h}$ at $37^{\circ} \mathrm{C}$ in shaking incubator $(250 \mathrm{rpm})$. From this, $1.8 \mathrm{ml}$ of cell suspension $\left(1 \times 10^{4} \mathrm{cfu} / \mathrm{ml}\right.$ of $E$. coli and Streptococcus mutans) was added into each well of 24- well microtitre plate containing glass slides. Then $100 \mu \mathrm{l} / \mathrm{ml}$ of CS/HA nanocomposite was added into the well. Nanocomposite free cell suspension wells served as control. The plates were kept in incubator at $37^{\circ} \mathrm{C}$ for $24 \mathrm{~h}$ under static condition. After incubation, the glass slides were carefully removed and washed twice with distilled water to remove non- attached excess cells and stained with $0.1 \%$ crystal violet for $15 \mathrm{~min}$ at room temperature. The stained slides were washed 2 to 3 times with distilled water and any remaining stains were washed by adding absolute ethanol for $15 \mathrm{~min}$. The biofilm was observed under light microscopy (Nikon) at the magnification of 40x. For visualizing under confocal laser scanning microscopy (CLSM), the glass slides were stained with $0.01 \%$ acridine orange ${ }^{16}$.

\section{RESULTS AND DISCUSSION}

Preparation and characteristics of CS/HA nanocomposite

The amino group present in the chitosan can form a bond with calcium phosphate ${ }^{17}$. In the modified solution-based method, the formation of CS/ HA hybrid material was carried out by the intermolecular interaction between the nucleated cationic amino group of chitosan and the anionic phosphate group of hydroxyapatite as per the following equation 1 and 2

$$
\begin{aligned}
& \mathrm{CS}-\mathrm{NH}_{2}+\mathrm{H}+\rightarrow \mathrm{CS}-\mathrm{NH}_{3}+ \\
& \mathrm{CS}-\mathrm{NH}_{3}++\mathrm{H}_{2} \mathrm{PO}_{4}-\rightarrow \mathrm{CSP}
\end{aligned}
$$

Amaral et al ${ }^{18}$ suggested that phosphorylated Chitosan showed the chemical modification which led to: (i) at hydroxyl group, Chitosan phosphate was esterified, (ii) electrostatic interaction between Chitosan phosphate and nucleated amino groups, (iii) condensation of chain occur. Here, the reaction between phosphorylated 
Chitosan (CSP) and $\mathrm{Ca}^{2+}$ and $\mathrm{OH}^{-}$ions took place to form CS/HA composites. Also, the formation of Hydroxyapatite was earned out by the reaction between calcium hydroxide and phosphoric acid (Equation 3 and 4)

$$
\begin{aligned}
& \mathrm{CSP}+\mathrm{Ca}_{2}++2 \mathrm{OH}-\rightarrow \mathrm{HA} / \mathrm{CS} \ldots(3) \\
& 10 \mathrm{Ca}(\mathrm{OH})_{2}+6 \mathrm{H}_{3} \mathrm{PO}_{4} \rightarrow \mathrm{Ca}_{10}\left(\mathrm{PO}_{4}\right) 6(\mathrm{OH})_{2}+
\end{aligned}
$$

$18 \mathrm{H}_{2} \mathrm{O}$

Dumont et al $^{17}$ suggested that the membrane was produced which contains an inorganic Hydroxyapatite core surrounded by organic Chitosan chains. This was explained by the Adapted LaMer model of nucleation. Alternately, the Chitosan changed to form worm-like complex structure at acidic $\mathrm{pH}$. During the formation of CS/ HA nanocomposite, Hydroxyapatite was occupied in the vacant space of the CS matrix. As a result, cluster-like structure was formed. Excessive water was removed during drying which helped to form a porous scaffold. The visual examination of dried nanocomposite scaffold showed physical characteristics such as colourless, stiff, and inelastic nature while the hydrated scaffold was soft, spongy, flexible and elastic as also indicated by previous studies and reports.

\section{Porosity}

High porosity was observed in prepared nanocomposites. Maximum porosity was observed in Chitosan: Hydroxyapatite nanocomposite with a ratio of $20: 80$ which showed $80-92 \%$ of porosity (Fig. 1). The low porosity of $74-89 \%$ was observed in Chitosan/ Hydroxyapatite composite at the ratio of $100: 5$ and 100:10. Porosities of $78-90 \%$ was recorded in the nanocomposite at the ratio of $80: 20$ and 50:50 which was approximately similar to the porosity of cancellous bone $(50-90 \%)^{19}$. The porosity helps to support cell adhesion and attachment with nutrients. From the data, increased porosities were observed with an increase in Hydroxyapatite under constant Chitosan. Oliveria et a ${ }^{20}$, suggested that the content of Hydroxyapatite was directly proportional to the porosity. The interaction between the polar functional group in Hydroxyapatite and Chitosan causes a high percentage of porosities in the nanocomposite. Hence, the porosity range reported from the result might be suitable for a bone implant.

\section{Water uptake and Retention ability}

To evaluate the biomaterial for tissue engineering, the hydrophilicity of the Chitosan polymer matrix is one of the critical features. This property is important for the absorption of body fluid and also helps to transfer cell nutrients and metabolites ${ }^{21}$. From the results obtained and as it could be noted from the Fig. 2 , the nanocomposite absorbed more water than their own weight, this is the reason the percentage is above $100.0 \%$ and also the scaffold showed maximum capacity to retain the absorbed water. The maximum water uptake ability was observed in Chitosan/ Hydroxyapatite composite with a ratio of $100 / 5$ which showed

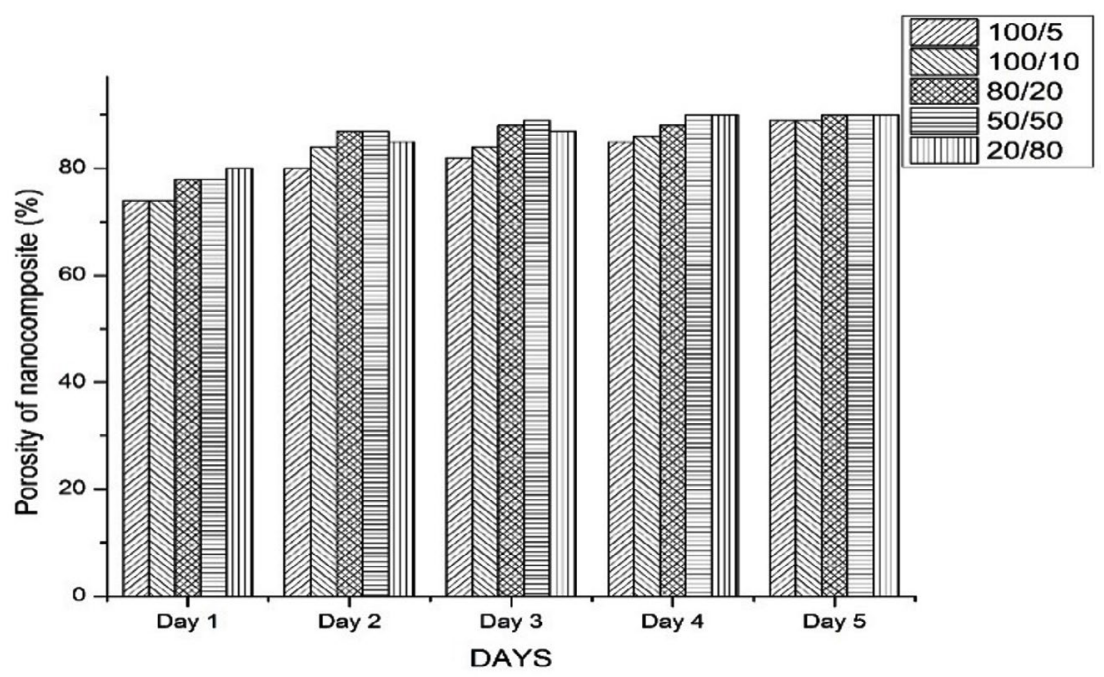

Fig. 1. Porosity (in \%) of nanocomposite with different ratios of Chitosan/ Hydroxyapatite 
102.0\% uptake and it maintained steadily until the completion of the experimental period. The lowest water uptake ability was observed in composite with the ratio of $20 / 80$ which showed $60.0 \%$. The result showed that water absorption ability was inversely proportional to the Hydroxyapatite present in the nanocomposite. Water retention ability data showed that scaffold can retain water to an extent as confirmed by the test, such that the tight aggregation of the polymeric chains might make the scaffolds stable in size and shape during contact with the implanted site ${ }^{22}$. Hydroxyapatite
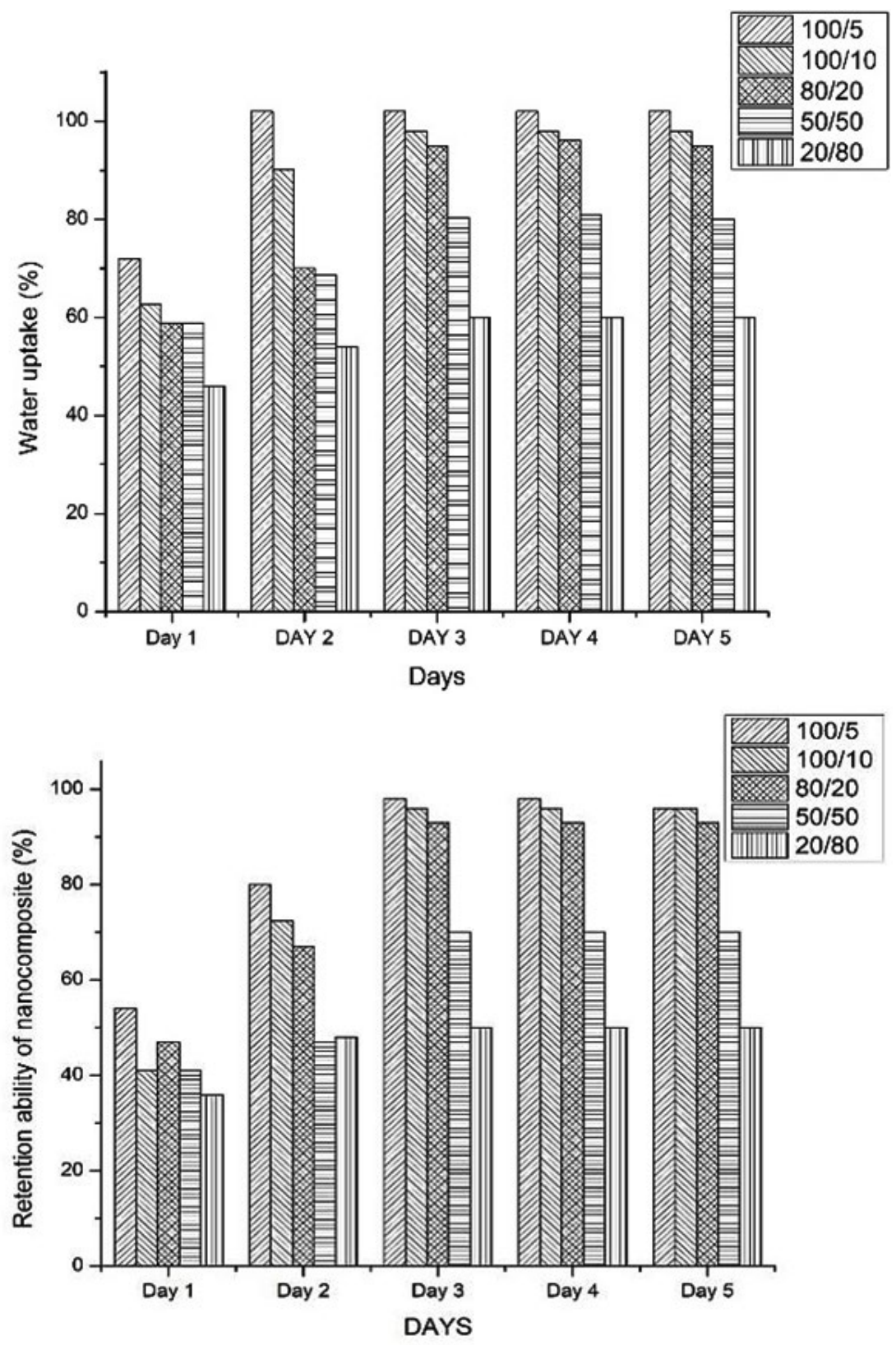

Fig. 2. Trend of water uptake (2a) and retention ability (2b) of nanocomposite with different ratios of Chitosan/ Hydroxyapatite: The nanocomposite absorbed more water than their weight and scaffold showed maximum capacity to retain the absorbed water 
Table 2. Degradation of different ratios of nanocomposite by lysozyme in body fluid

\begin{tabular}{lccccc}
\hline \multirow{2}{*}{$\begin{array}{l}\text { CS/HA } \\
\text { composite }\end{array}$} & \multicolumn{5}{c}{ Degradation percentage (\%) } \\
\cline { 2 - 6 } & $3^{\text {rd }}$ day & $6^{\text {th }}$ day & $9^{\text {th }}$ day & $12^{\text {th }}$ day & $15^{\text {th }}$ day \\
\hline $100 / 5$ & 1.97 & 1.97 & 2.63 & 2.63 & 2.63 \\
$100 / 10$ & 0.65 & 1.30 & 2.60 & 3.25 & 3.25 \\
$80 / 20$ & 3.33 & 4 & 6 & 6 & 6 \\
$50 / 50$ & 0 & 0.65 & 1.3 & 2.6 & 2.6 \\
$20 / 80$ & 3.47 & 6.08 & 7.83 & 7.83 & 7.83 \\
\hline
\end{tabular}

content depends on the water uptake ability under the fixed content of Chitosan. The presence of Hydroxyapatite has contributed not only to the reduced water uptake ability of nanocomposite but also increased the stiffness of nanocomposite.

\section{pH and Enzymatic degradation study}

Enzymatic degradation was carried out using lysozyme to provide the physiological environment and to investigate the biodegradation nature of the implant is essential for bone tissue engineering. Degradation rate of Chitosan composites was studied using the enzyme lysozyme and the degradation percentage of the composite have been listed in Table 2. From the data, it could be observed that there was no significant mass loss. All these composites showed low degradation ability as they did not attain $10.0 \%$ degradation rate. Thein- Han \& Mirsa ${ }^{14}$ indicated that the molecular weight of Chitosan and amount of nano-hydroxyapatite showed a negligible change in degradation rate after 28 days of degradation study. Also, by using

Table 3. Zone of inhibition of nanocomposite against different pathogen

\begin{tabular}{lccccc}
\hline \multirow{2}{*}{ Microbial strains } & \multicolumn{5}{c}{ Zone of inhibition (mm) } \\
\cline { 2 - 6 } & Streptomycin & Chitosan & HA & $\begin{array}{c}\text { CS/HA } \\
\text { nanocomposite }\end{array}$ \\
\hline E. coli & 22 & 12 & - & 9 & 12.5 \\
Staphylococcus aureus & 24 & 11 & - & 9 & 12 \\
Klebsiella pneumoniae & 19 & 9 & - & 7 & 11 \\
Pseudomonas aeruginosa & 28 & 12 & - & 10 & 10.5 \\
Serratia marcescens & 30 & 12 & - & 8 & 10 \\
Candida albicans & - & 12 & - & 11.5 \\
\hline
\end{tabular}

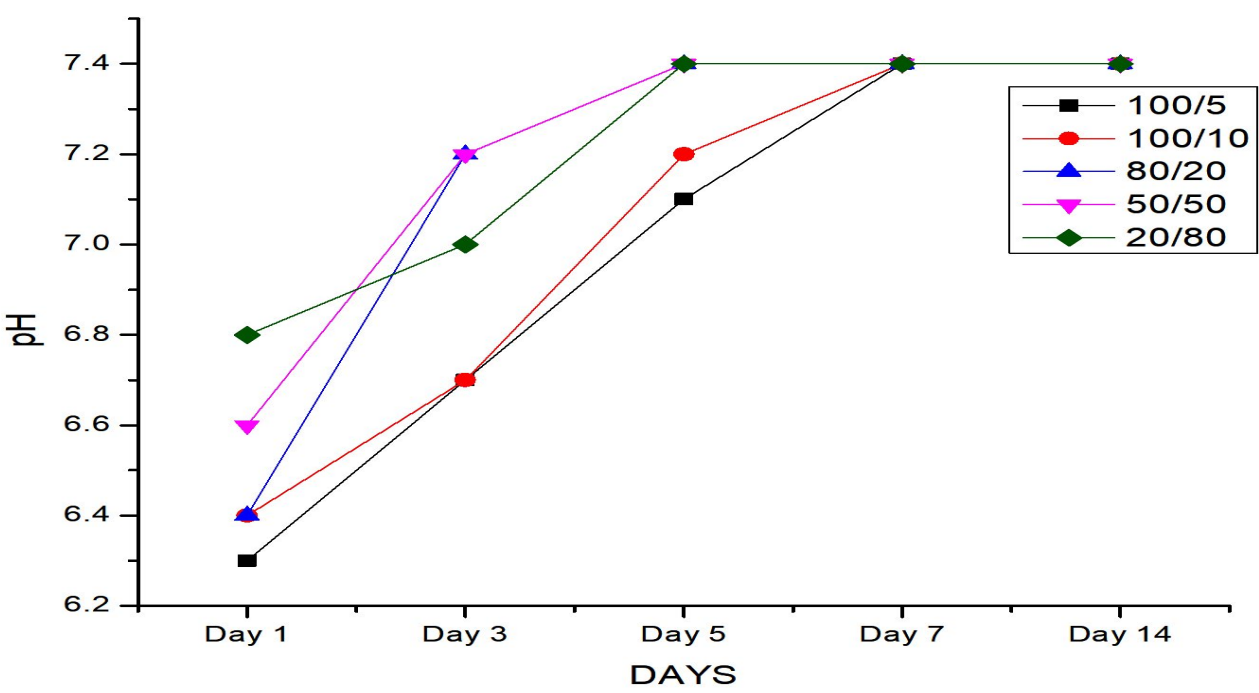

Fig. 3. Trend of fluctuation of $\mathrm{pH}$ value of the scaffold at different days:

The $\mathrm{pH}$ value of the scaffold placed in the physiological solution was 6.4 on the 1 st day. $\mathrm{pH}$ value increased gradually and reached at 7.4 on 5 th day which is similar to the $\mathrm{pH}$ of human plasma (7.4) 
a microsphere-based technique, the prepared Chitosan/ nanocrystalline calcium phosphate and Chitosan scaffold showed negligible weight loss and insignificant morphological change as observed through SEM for 14 days degradation study in PBS with lysozyme ${ }^{23}$. The low degradation rate observed is due to the high deacetylation degree and crystallinity of Chitosan indicating that the degradation rate was inversely proportional to the degree of deacetylation. It is also pertinent to ponder that for constructing a bone implant for tissue engineering, extra attention is needed to

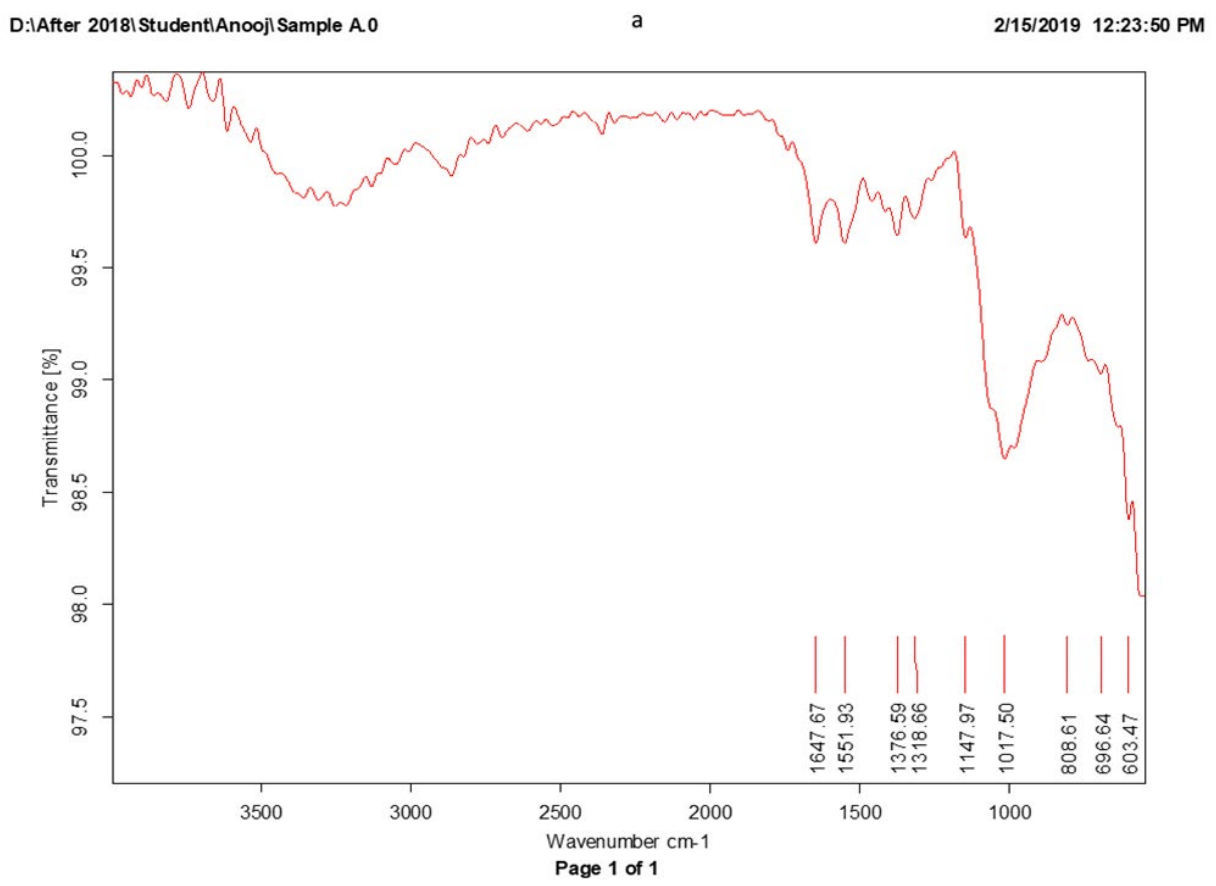

$\begin{array}{lll}\text { D:IAfter 2018IStudent|Anoojl Sample B.0 } & \text { b } & \text { 2/15/2019 12:28:02 PM }\end{array}$

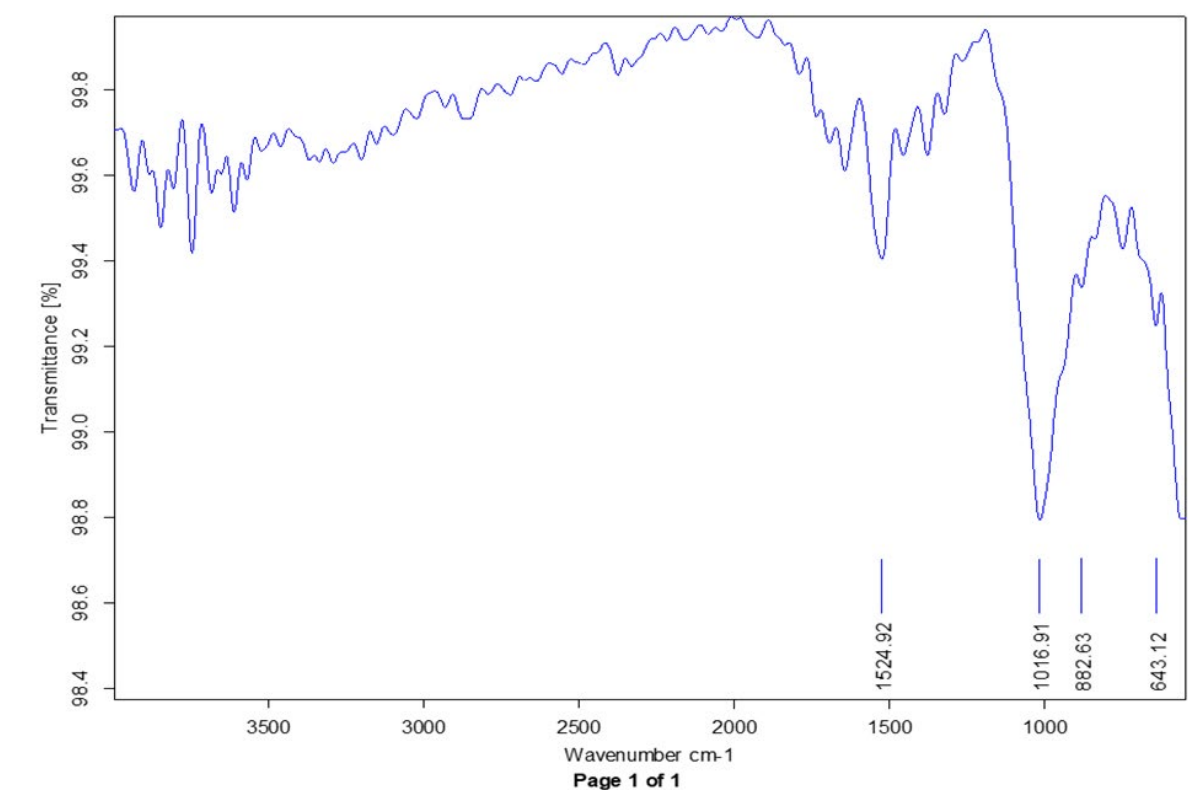

Journal of Pure and Applied Microbiology

1462

www.microbiologyjournal.org 
the parameters like molecular weight, degree of deacetylation and and degradation of Chitosan. The biodegradation between Chitosan and Hydroxyapatite was very strong. Thus, it is very hard to break the linkage by using lysozyme. For the above reason, the degradation rate of this prepared nanocomposite is very slow and hence these are applicable in the bone tissue engineering processes.

Using physiological saline solution, the $\mathrm{pH}$ value of the scaffold was noted for 14 days and the results are presented in Fig. 3. On the first day, the
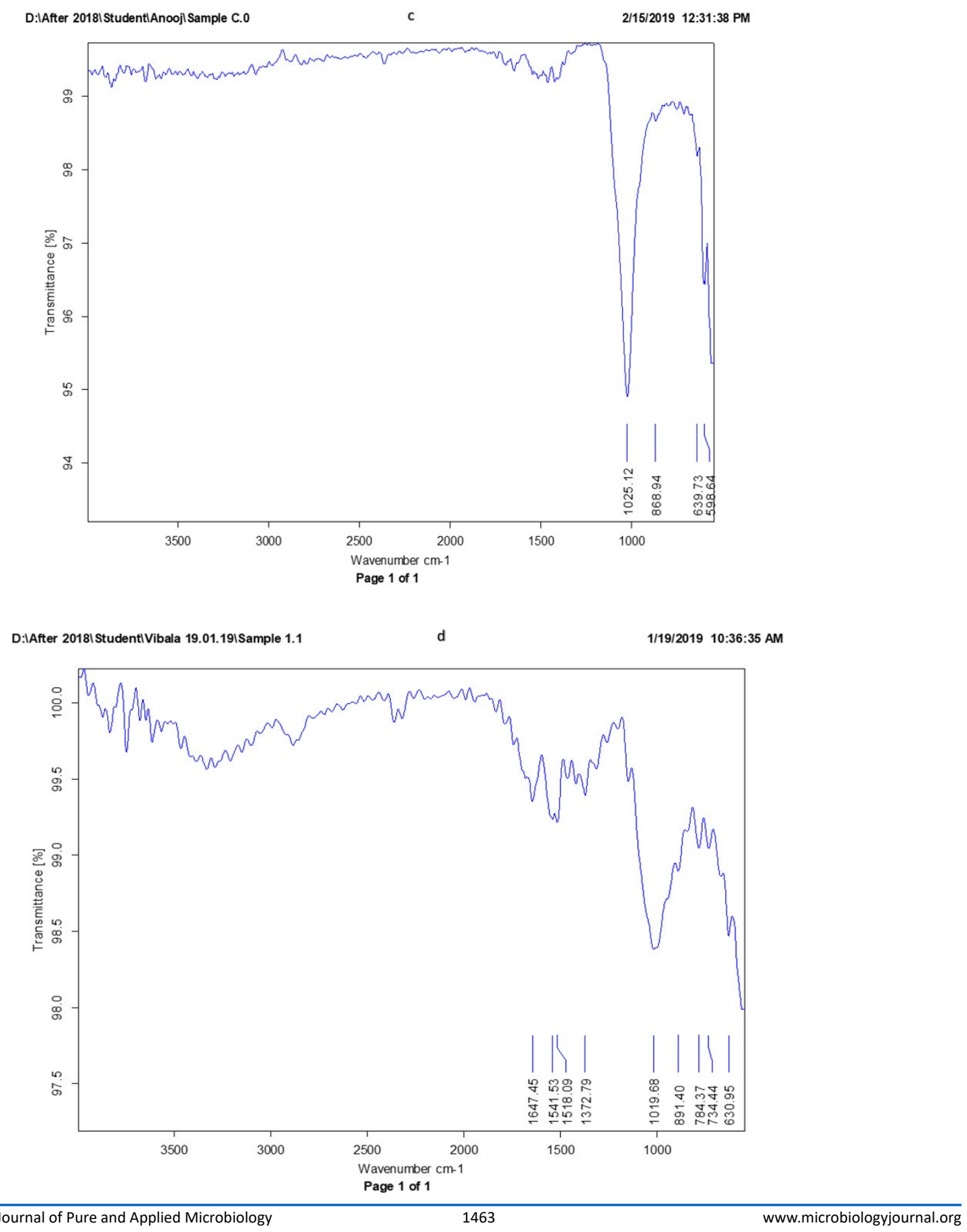


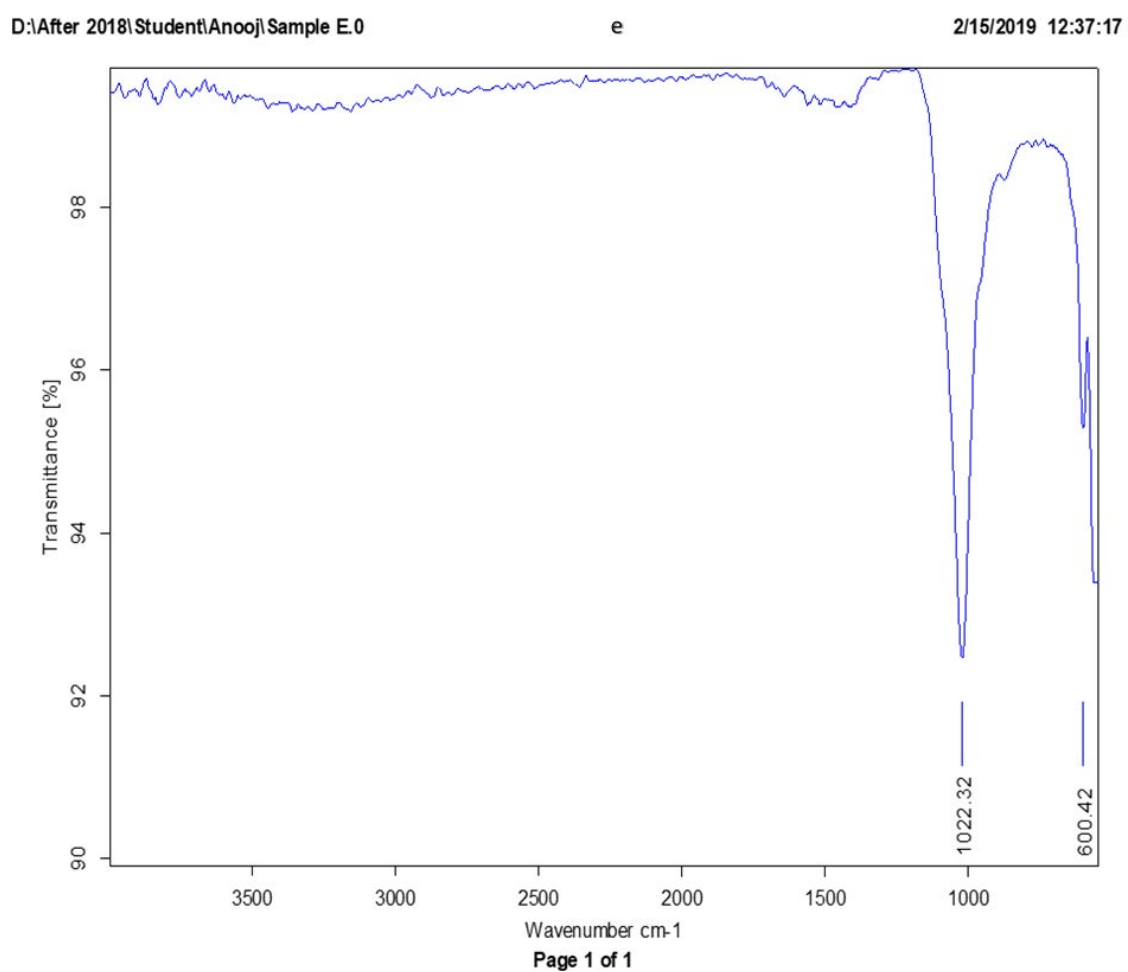

Fig. 4. (a to e). FTIR spectra of different ratios of chitosan/hydroxyapatite nanocomposite (CS/HA) a. Chitosan/ Hydroxyapatite ratio: 100/5, b. Chitosan/ Hydroxyapatite ratio: 100/10,

c. Chitosan/ Hydroxyapatite ratio: $80 / 20$, d. Chitosan/ Hydroxyapatite ratio: 50/50,

e. Chitosan/ Hydroxyapatite ratio $20 / 80$

$\mathrm{pH}$ value of the scaffold kept in the physiological solution was 6.4 . From the 5 th day onwards, the $\mathrm{pH}$ value increased gradually and reached at 7.4 which is similar to that of the $\mathrm{pH}$ of human plasma (7.4). This value was retained throughout the total duration of the experimental period of 14 days. As the $\mathrm{pH}$ value of the scaffold was similar to the human plasma (7.4), it could be considered as non-toxic to human.

\section{Phase composition}

FTIR was carried out to determine the interaction between Chitosan polymer and bioactive component Hydroxyapatite. The results of FTIR spectra of Chitosan/ Hydroxyapatite composites with different ratio are presented in Fig. 4 (a to e). From the FTIR spectra, the carbonate group presents in the Chitosan had appeared in the Chitosan/ Hydroxyapatite nanocomposite. The absorption bands at 1645, 1575 and 1375 $\mathrm{cm}-1$ were indicated as amide I $(\mathrm{C}=0)$, amino $\left(-\mathrm{NH}^{2}\right)$ and amide II (-NH) groups, respectively.
At $3600 \mathrm{~cm}^{1}$, there was a weak band observed because of the presence of absorbed water in the nanocomposite. The presence of phosphate group in Hydroxyapatite was identified by the absorption bands at 1017, 808, 603 and $595 \mathrm{~cm}^{-}$ ${ }^{1}$. In Chitosan/ Hydroxyapatite nanocomposite, the intermolecular bridging complexes were formed which represented the $\mathrm{N}-\mathrm{H}$ bonding peaks as observed at a slight shift from $1595 \mathrm{~cm}^{-119}$. During the formation of CS/HA nanocomposite, the amino group present in the Chitosan was formed a coordination bond with calcium ion in Hydroxyapatite ${ }^{24}$. This formation leads to the further arrangements of small Hydroxyapatite particles into the Chitosan molecule so as to form aggregates. Thus, it is evident that the particle size of Hydroxyapatite had directly affected in the formation of CS/HA nanocomposite. FTIR result clearly showed the strong bonding between the Chitosan/ Hydroxyapatite composite as reported earlier. 
High temperature will be used for the sterilization of biomedical implants. Thus, it is necessary to check the thermal characteristics of biomedical substances, not only the temperature limits of the human body, but also for the sterilization temperature of material. The sample was heated in a nitrogen atmosphere to determine the thermal stability of CS/HA nanocomposite. It reveals that when the temperature increases, the weight of the composite decreaseds. From the

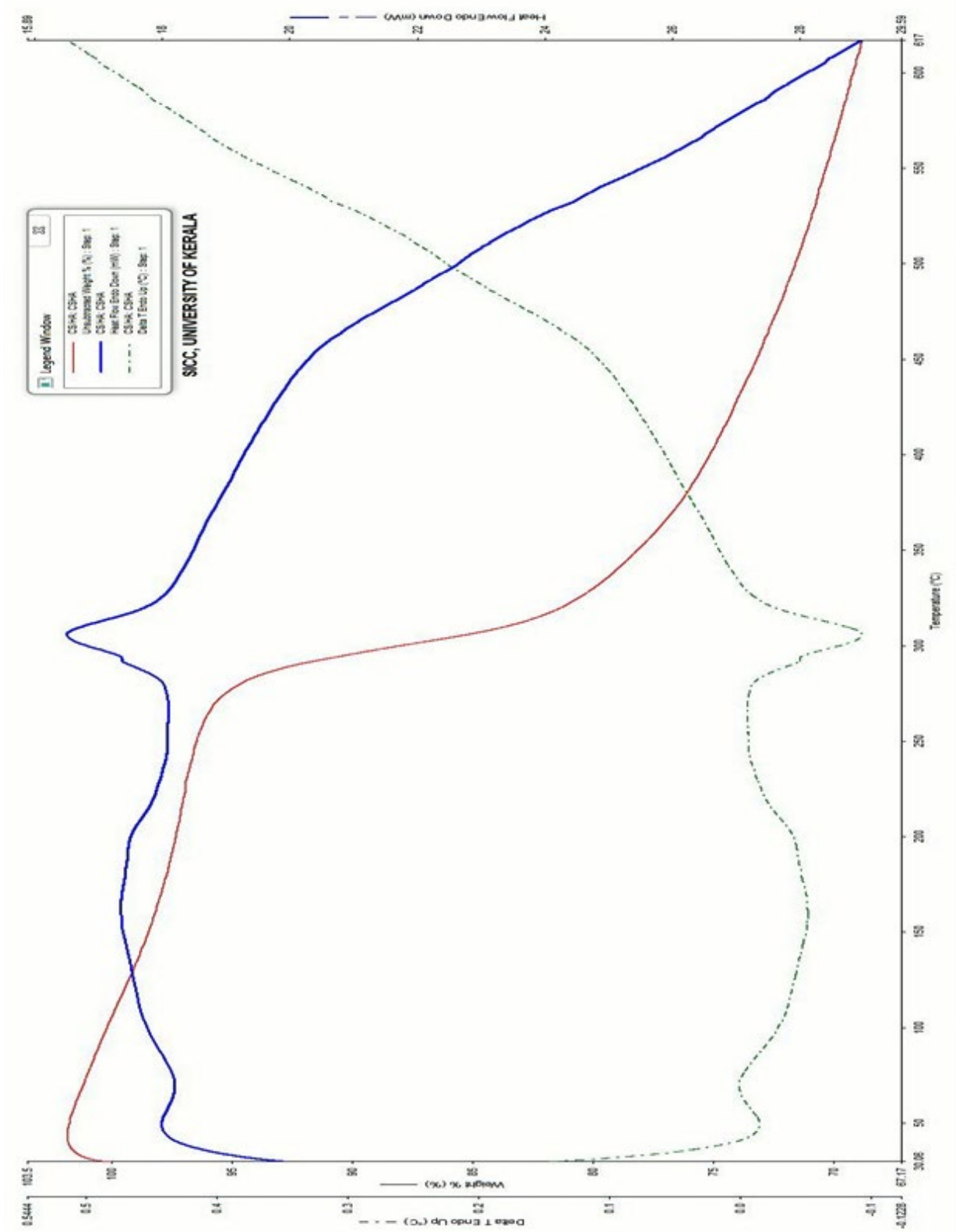

Fig. 5. TG- DTC- DSC curves of chitosan/Hydroxyapatite nanocomposite:

The composite showed weight loss at $30-120^{\circ} \mathrm{C}, 270-320^{\circ} \mathrm{C}$ and $320-600^{\circ} \mathrm{C}$. The weight loss at $30-120^{\circ} \mathrm{C}$ could be due to the release of water present in the sample. However, at $270-320^{\circ} \mathrm{C}$ and $320-600^{\circ} \mathrm{C}$, the weight loss can be attributed to the thermal combusting of chitosan. 
Table 4. MIC, MBC (24h) value of nanocomposite towards different microbial pathogens

\begin{tabular}{lcc}
\hline Microorganisms & $\begin{array}{c}\text { MIC } \\
(\mu \mathrm{l} / \mathrm{ml})\end{array}$ & $\begin{array}{c}\mathrm{MBC} \\
(\mu \mathrm{l} / \mathrm{ml})\end{array}$ \\
\hline E. coli & 300 & 500 \\
Pseudomonas aeruginosa & 300 & 500 \\
Klebsiella pneumoniae & 400 & 500 \\
Staphylococcus aureus & 400 & 500 \\
Candida albicans & 300 & 500 \\
\hline
\end{tabular}

result, the composite showed weight loss at 30$120^{\circ} \mathrm{C}, 270-320^{\circ} \mathrm{C}$ and $320-600^{\circ} \mathrm{C}$. The weight loss at $30-120^{\circ} \mathrm{C}$ could be due to the release of water present in the sample. However, at $270-320^{\circ} \mathrm{C}$ and $320-600^{\circ} \mathrm{C}$, the weight loss can be attributed to the thermal combusting of Chitosan (Fig. 5).
The release of water present in the sample was contributed to an endothermic process at $37^{\circ} \mathrm{C}$. Shakir et $\mathrm{al}^{25}$ identified that the TGA graph of CS/ $\mathrm{HA}$ composite had weight-loss event at $90-150^{\circ} \mathrm{C}$ and $100-400^{\circ} \mathrm{C}$ with $\sim 70-72 \%$ weight loss. This revealed that the $\mathrm{n}-\mathrm{HA}$ raised the thermal stability of CS indicating the interaction between $n-\mathrm{HA}$ and CS.

The mesoporous structure of Chitosan/ Hydroxyapatite nanocomposite was visualized using SEM (Fig. 6). SEM images at high and low magnification clearly indicated that the Chitosan acted as a scaffolding matrix forming CS/HA nanocomposite. Images also showed numerous individual pores with different sizes which were linked together to produce a porous network. This structure encourages the cell growth into
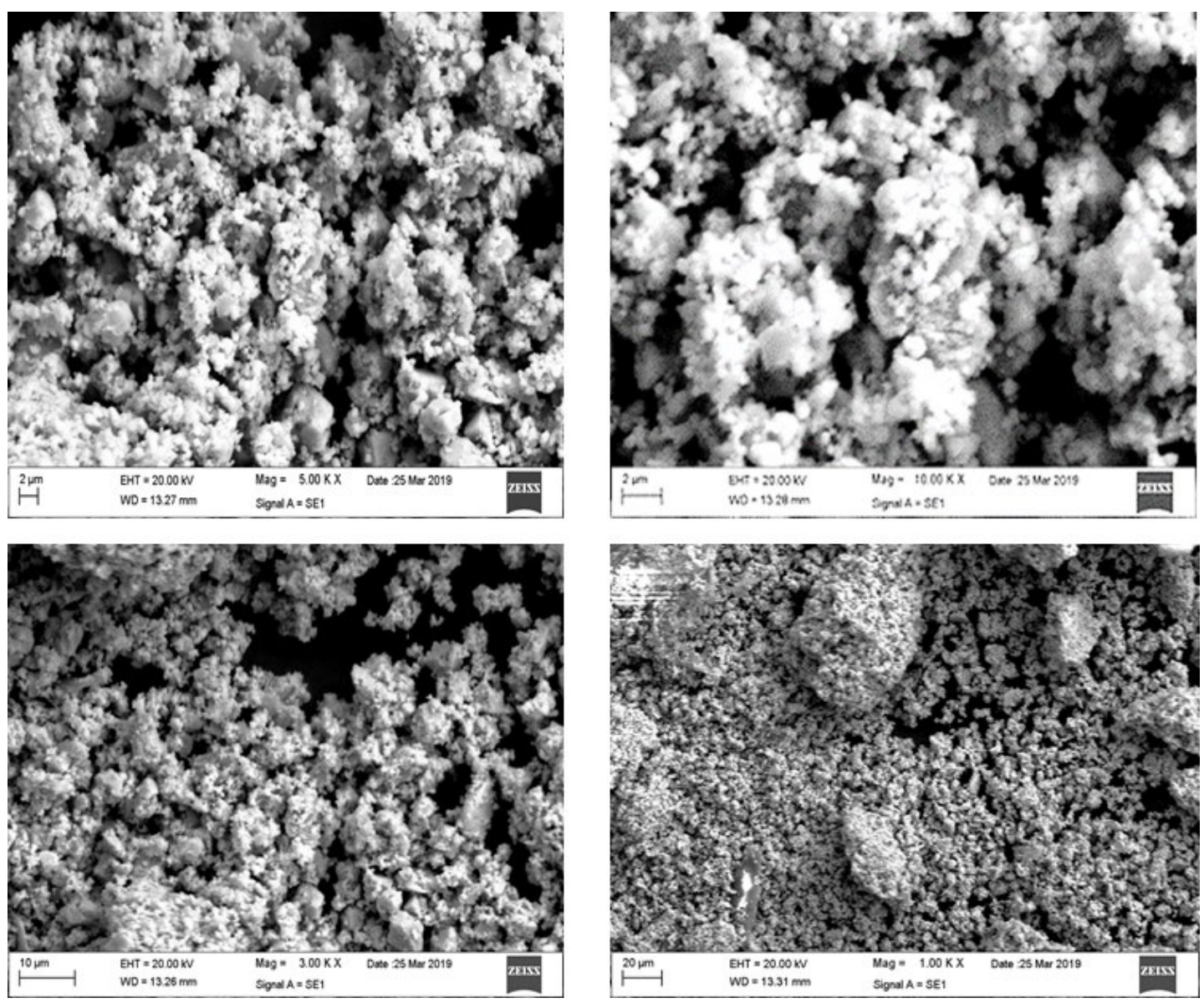

Fig. 6. High and low magnification SEM images of CS/HA scaffold with the ratio of 50/50:

Chitosan acted as a scaffolding matrix forming CS/HA nanocomposite and also numerous individual pores with different sizes which were linked together to produce a porous network. 


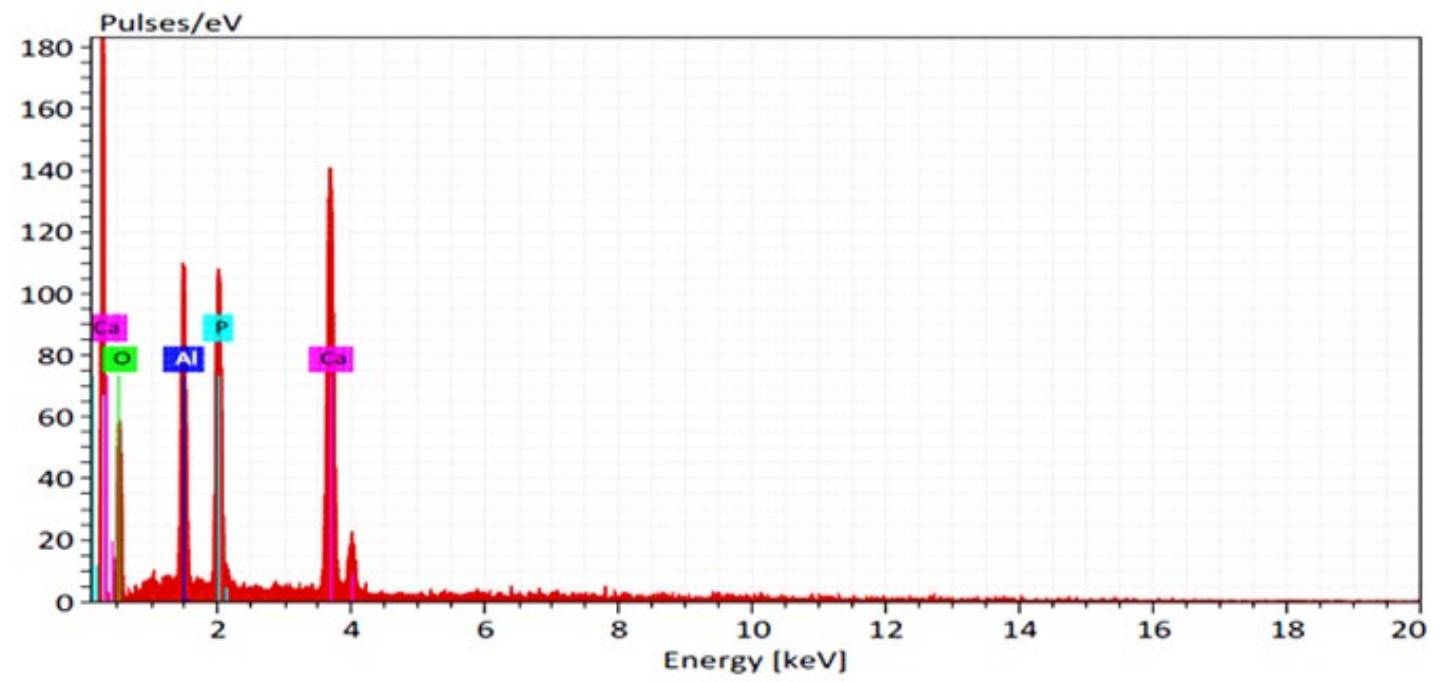

Fig. 7. EDX pattern of chitosan/hydroxyapatite nanocomposite:

The $\mathrm{Ca} / \mathrm{P}$ ratio of sample detected by EDX analysis, which was nearly similar to that of apatite (1.67) confirming $\mathrm{CS} / \mathrm{HA}$ nanocomposite mimics the natural bone.
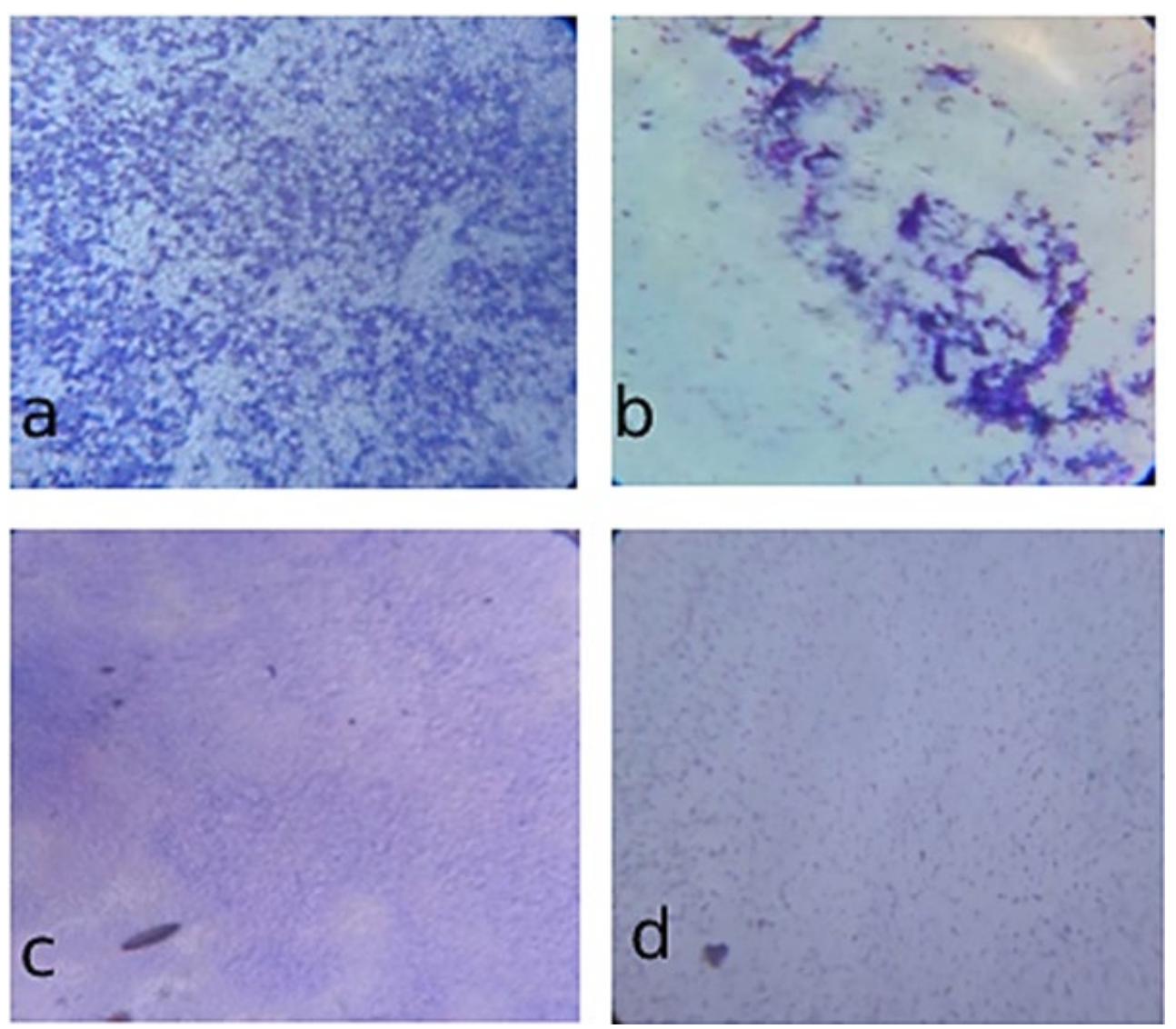

Fig. 8A. Light microscopic observation of inhibitory effects of Chitosan/Hydroxyapatite nanocomposite on biofilm formation

(a). Streptococcus mutans- control; (b) Streptococcus mutans- test; (c). E. coli- control; (d). E. coli- test 
the cavity and helps to supplement the blood and nutrition through circulation and penetration. Therefore, these pores help the bone tissue ingrowth into the implant material. The $\mathrm{Ca} / \mathrm{P}$ ratio of sample detected by SEM- EDX analysis (Fig. 7), which was nearly similar to that of apatite (1.67) confirming CS/HA nanocomposite mimics the natural bone.

\section{Antimicrobial activity}

The nanocomposite with antimicrobial activity was advantageous for the success of bone tissue engineering. The antimicrobial activity was evaluated for nanocomposite against five different clinical pathogen bacterial strains viz., E. coli, Staphylococcus aureus, Klebsiella pneumoniae, Pseudomonas aeruginosa and Serratia marcescens and one fungal clinical pathogen strain Candida albicans. The maximum bactericidal activity was observed for Chitosan/ Hydroxyapatite nanocomposite against Serratia marcescens and Pseudomonas aeruginosa which showed a clear zone of inhibition of $10 \mathrm{~mm}$ (Table 3). The nanocomposite also showed a zone of inhibition of $9 \mathrm{~mm}$ against $S$. aureus and $E$. coli and for Candida albicans, it was $8 \mathrm{~mm}$. The minimum bactericidal activity was observed against Klebsiella pneumoniae which showed a zone of inhibition of $7 \mathrm{~mm}$. Chitosan has antimicrobial properties ${ }^{26-28}$. Chitosan was applied in many industries such as food, agriculture, and wound dressing due to their antibacterial activity against both gram-positive and gram-negative organisms ${ }^{28}$. Chitosan affects the microbial growth by membrane disruption, loss of cellular protein and change in membrane permeability. Degree of deacetylation, molecular weight, $\mathrm{pH}$, temperature, viscosity and ionic strength of the medium, solvent, type of microorganism and growth stage etc. are the major factors which influenced the antimicrobial activity of Chitosan ${ }^{29,30}$. The activities were largely dependent on the presence of Chitosan within the composite, and it was noted that the presence of Hydroxyapatite did not affect the ability to reduce microbial growth.

Minimum inhibitory concentration and Minimum bactericidal concentration

The minimum concentration of composite that was able to suppress the growth of bacteria
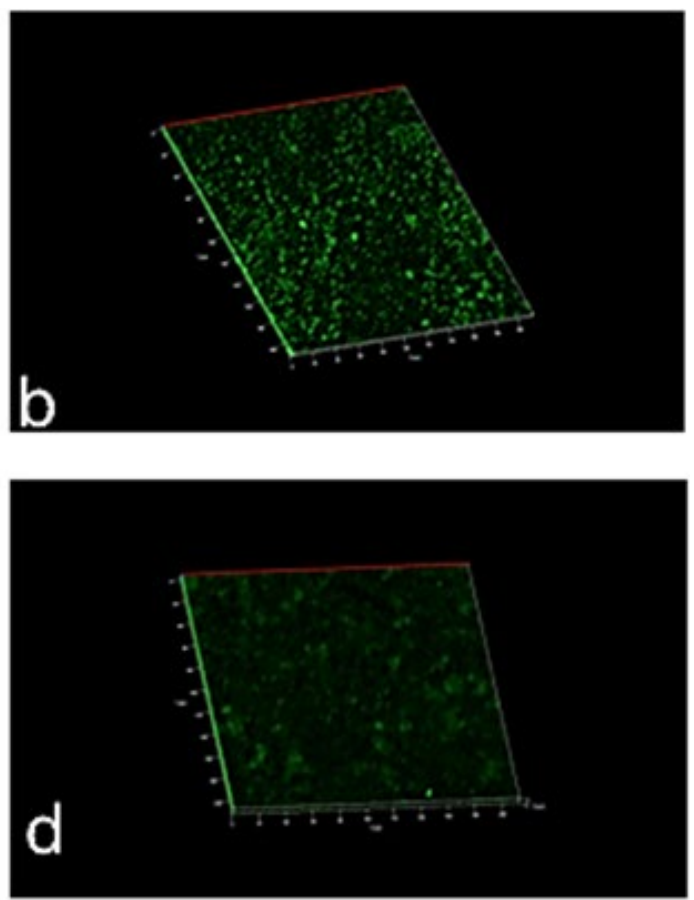

Fig. 8B. Confocal microscopic observation of inhibitory effects of Chitosan/Hydroxyapatite nanocomposite on biofilm formation (a). Streptococcus mutans- control; (b) Streptococcus mutans- test; (c). E. coli- control; (d). E. coli- test 
was considered as the MIC (Minimum Inhibitory Concentration) and the minimum concentration of composite capable of preventing the growth of $99 \%$ of the bacteria was assumed to be as MBC (Minimum Bactericidal Concentration). The MBC test was carried out with $24 \mathrm{~h}$ incubation as given in the Methodology. From the table 4, it could be observed that the Chitosan/ Hydroxyapatite nanocomposite at the concentration of $300 \mu \mathrm{l} /$ $\mathrm{ml}$ inhibited the growth of microorganisms such as Pseudomonas aeruginosa, E. coli and Candida albicans and at the concentration of $400 \mu \mathrm{l} / \mathrm{ml}$ nanocomposite, it inhibited the growth of bacterial strain Klebsiella pneumoniae and Staphylococcus aureus. The nanocomposite showed microbicidal activity at the concentration of $500 \mu \mathrm{l} / \mathrm{ml}$. That is, Chitosan/ Hydroxyapatite nanocomposite prevent the growth of all the five tested microorganisms at the concentration of $500 \mu \mathrm{l} / \mathrm{ml}$. From the data, it could be concluded that the MBC ( $24 \mathrm{~h}$ ) value of nanocomposite against these five strains was 500 $\mu \mathrm{l} / \mathrm{ml}$.

MIC and MBC results showed that CS/ HA nanocomposites have antimicrobial activity against all tested bacterial strains. That means it shows a wide range of antimicrobial activity due to the electrostatic bond between the amino group in nanocomposite and positively charged phosphoryl group in the cell membrane. It leads to the instability of the cytoplasmic membrane that resulted in cell death ${ }^{23}$. Hence, it is proven that that these composites interrupted the formation of cell wall.

\section{Biofilm inhibition assay}

Effect of Chitosan/ Hydroxyapatite nanocomposite over the biofilm formation on glass surface was visualized under both light and confocal microscopy (Fig. 8 A \& B). This analysis revealed that the control slides showed well developed biofilm growth and whereas bacterial biofilm treated with the CS/HA nanocomposite showed reduced biofilm on glass slides. The inhibition of biofilm formation of gram positive (Streptococcus mutans) bacteria was comparatively more than that of gram negative (E. coli) bacteria. Carlson et $\mathrm{al}^{31}$ concluded that Chitosan-coated surfaces have antibiofilm properties against fungi and bacteria in-vitro. This has been attributed to the ability of cationic Chitosan to disrupt the negatively charged cell membrane when microbes settle on the surface ${ }^{26}$. Chitosan reduced the metabolic activity and survival of the microbial biofilm. This can be caused by physical stress on the biofilm structures due to permeability of the cell membrane, which allows increased penetration of Chitosan and effective release of its antimicrobial activity ${ }^{29}$. From the results, the nanocomposite showed good antibiofilm properties and thereby corroborate the previous investigations.

\section{CONCLUSION}

Novel organic-inorganic Chitosan/ Hydroxyapatite nanocomposites were prepared through a simple blend method to overcome the prevailing challenges in proper dispersion of particles in the CS/HA nanocomposite scaffolds. A notable HA degradation could be established in the Chitosan matrix. The ability of water absorption of the composite was directly proportional to the content of Chitosan as it increases with the proportional increase in the concentration of Chitosan. The analysis such as FTIR and SEM-EDX illustrated the bony apatite layer formation on the outside of the composites. Also, HA particle deposition on the surface of the composite was increased with the incorporation of Chitosan. The antimicrobial activity was tested and confirmed that it largely dependent on the presence of Chitosan within the composite, and it was noted that the presence of Hydroxyapatite did not affect the ability to reduce microbial growth. The nanocomposite showed good antibiofilm properties and thereby corroborate the previous investigations. These evidences highlight that these nanocomposites could be applicable for the bone-implant and used in the future bio application methods.

\section{ACKNOWLEDGMENTS}

The authors are thankful to the Tamil Nadu State Council for Science and Technology and DST-NPDF for the financial support.

\section{CONFLICT OF INTEREST}

The authors declare that there is no conflict of interest. 


\section{AUTHORS' CONTRIBUTION}

SGPV and ANL conceived and planned the experiments. AF and ANL carried out the experiments. All authors provided critical feedback and helped shape the research, analysis, and manuscript.

\section{FUNDING}

This study was funded by Tamil Nadu State Council for Science and Technology (BS026) and co-funded by DST-NPDF (PDF/2016/002502).

\section{DATA AVAILABILITY}

All datasets generated or analyzed during this study are included in the manuscript.

\section{ETHICS STATEMENT}

This article does not contain any studies with human participants or animals performed by any of the authors.

\section{REFERENCES}

1. Vande VP, Matthew HWT, Desilva SP, Mayton L, Wu $\mathrm{B}$, Wooley $\mathrm{PH}$. Evaluation of the biocompatibility of chitosan scaffold in mice. J Biomed Mater Res. 2002;59(3):585-590. doi: 10.1002/jbm.1270

2. Lee JY, Nam SH, I'm SY, et al. Enhanced bone formation by controlled growth factor delivery from chitosanbased biomaterials. J Control Release. 2002;78(1 3):187-197. doi: 10.1016/S0168-3659(01)00498-9

3. Eugene K, Lee YL. Implantable application of chitin and chitosan. Biomaterials. 2003;24(13):2339-2349. doi: 10.1016/S0142-9612(03)00026-7

4. Gupta KC, Kumar MNR. pH-dependent hydrolysis and drug release behavior of chitosan/poly (ethylene glycol) polymer network microspheres. J Mater Sci Mater Med. 2001;12(9):753-759. doi: 10.1023/A:1017976014534

5. Sabokbar A, Pandey R, Diaz J, Quinn JMW, Murray DW, Athanasou NA. Hydroxyapatite particles are capable of inducing osteoclast formation. J Mater Sci Mater Med. 2001;12(8):659-664. doi: 10.1023/A:1011267005465

6. Javed $S$, Noreen R, Kamal S, Rehman S, Yaqoob $\mathrm{N}$, Abrar S. Polymer blends as matrix materials for the preparation of the nanocomposites. Bionanocomposites: Green Synthesis and Application Micro and Nano Technologies, ed. K Mahmood Zia, F Jabeen, MN Anjum, S Ikram, Elsevier, Amsterdam, Netherlands. 2020;21-54. doi: 10.1016/B978-0-12816751-9.00002-7

7. Rana D, Mandal BM, Bhattacharyya SN. Analogue calorimetry of polymer blends: poly (styrene-coacrylonitrile) and poly (phenyl acrylate) or poly (vinyl benzoate). Polymer. 1996;37(12):2439-2443. doi: 10.1016/0032-3861(96)85356-0
8. Rana D, Cho K, Lee BH, Choe S. Is metallocene polyethylene blend with HDPE more compatible than with PP?. Metallocene Technology in Commercial Applications. 1999;17.

9. Rana D, Cho K, Woo T, Lee BH, Choe S. Blends of ethylene 1-octene copolymer synthesized by Ziegler-Natta and metallocene catalysts. I. Thermal and mechanical properties. J Appl Polym Sci. 1999;74(5):1169-1177. doi: $10.1002 /(\mathrm{SICl}) 1097-$ 4628(19991031)74:5<1169::AID-APP13>3.0.CO;2-W

10. Ibrahim M, Abdel-Fattah WI, El-Sayed ESM, Omar A. A novel model for Chitosan/Hydroxyapatite Interaction. Quantum Matter. 2013;2(3):234-237. doi: 10.1166/ qm.2013.1053

11. Yelten-Yilmaz A, Yilmaz S. Wet chemical precipitation synthesis of hydroxyapatite (HA) powders. Ceramics International. 2018;44(8):9703-9710. doi: 10.1016/j. ceramint.2018.02.201

12. Li BQ, Qiao-Ling $H$, Wang $M$, Shen JC. Preparation of chitosan/hydroxyapatite nanocomposite with layered structure via in-situ compositing. Chemical Journal of Chinese Universities-Chinese Edition-, 2004 ;25(10):1949-1952.

13. Zhang $Y$, Zhang $M$. Synthesis and characterization of macroporous chitosan/calcium phosphate composite scaffolds for tissue engineering. J Biomed Mater Res. 2001;55(3):304-312.doi: 10.1002/1097-4636(20010605)55:3<304::AIDJBM1018>3.0.CO;2-J

14. Thein-Han WW, Misra RDK. Biomimetic chitosannanohydroxyapatite composite scaffolds for bone tissue engineering. Acta Biomater. 2009;5(4):11821197. doi: 10.1016/j.actbio.2008.11.025

15. Ansari NF, Amirul AA. Preparation and characterization of polyhydroxyalkanoates macroporous scaffold through enzyme-mediated modifications. Appl Biochem Biotechnol. 2013;170(3):690-709. doi: 10.1007/s12010-013-0216-0

16. Selvaraj C, Sivakamavalli J, Vaseeharan B, Singh P, Singh SK. Structural elucidation of SrtA enzyme in Enterococcus faecalis: an emphasis on screening of potential inhibitors against the biofilm formation. Mol BioSyst. 2014;10(7):1775-1789. doi: 10.1039/ C3MB70613C

17. Dumont J, Euwart D, Mei B, Estes S, Kshirsagar R. Human cell lines for biopharmaceutical manufacturing: history, status, and future perspectives. Crit Rev Biotechnol. 2016;36(6):1110-1122. doi: 10.3109/07388551.2015.1084266

18. Amaral IF, Granja PL, Barbosa MA. Chemical modification of chitosan by phosphorylation: an XPS, FT-IR and SEM study. J Biomater Sci Polym Ed. 2005;16(12):15751593. doi: $10.1163 / 156856205774576736$

19. Liu H, Webster TJ. Nanomedicine for implants: a review of studies and necessary experimental tools. Biomaterials. 2007;28(2):354-369. doi: 10.1016/j. biomaterials.2006.08.049

20. Oliveira GB, Carvalho Jr LB, Silva MPC. Properties of carbodiimide treated heparin. Biomaterials. 2003;24(26):4777-4783. doi: 10.1016/S01429612(03)00376-4

21. Hu Q, Li B, Wang M, Shen J. Preparation and 
characterization of biodegradable chitosan/ hydroxyapatite nanocomposite rods via in situ hybridization: a potential material as internal fixation of bone fracture. Biomaterials. 2004;25(5):779-785. doi: 10.1016/S0142-9612(03)00582-9

22. Chesnutt BM, Viano AM, Yuan $\mathrm{Y}$, et al. Design and characterization of a novel chitosan/nanocrystalline calcium phosphate composite scaffold for bone regeneration. J Biomed Mater Res A. 2009;88(2):491502.doi: 10.1002/jbm.a.31878

23. Crismaru M, Asri LA, Loontjens TJ, et al. Survival of adhering staphylococci during exposure to a quaternary ammonium compound evaluated by using atomic force microscopy imaging. Antimicrob Agents Chemother. 2011;55(11):5010-5017. doi: 10.1128/ AAC.05062-11

24. Yamaguchi I, Tokuchi K, Fukuzaki H, Koyama Y, Takakuda K, Monma H. Preparation and microstructure analysis of chitosan/hydroxyapatite nanocomposites. J Biomed Mater Res. 2001;55(1):2027. doi: 10.1002/1097-4636(200104)55:1<20::AIDJBM30>3.0.CO;2-F

25. Shakir M, Jolly R, Khan AA, et al. Resol based chitosan/ nano-hydroxyapatite nano assembly for effective bone tissue engineering. Carbohydrate Polymers. 2018;179:317-327. doi: 10.1016/j.carbpol.2017.09.103
26. Rabea EI, Badawy MET, Stevens CV, Smagghe G, Steurbaut W. Chitosan as antimicrobial agent: applications and mode of action. Biomacromolecules. 2003;4(6):1457-1465. doi: 10.1021/bm034130m

27. Jayakumar R, Prabaharan M, Kumar PS, Nair SV, Tamura $\mathrm{H}$. Biomaterials based on chitin and chitosan in wound dressing applications. Biotechnol Adv. 2011;29(3):322337. doi: 10.1016/j.biotechadv.2011.01.005

28. Kong $M$, Chen XG, Xing K, Park HJ. Antimicrobial properties of chitosan and mode of action: a state of the art review. Int J Food Microbiol. 2010;144(1):51-63. doi: 10.1016/j.ijfoodmicro.2010.09.012

29. Raafat D, Sahl HG. Chitosan and its antimicrobial potential-a critical literature survey. Microbial Biotechnol. 2009;2(2):186-201. doi: 10.1111/j.17517915.2008.00080.x

30. Vazquez-Sanchez D, Cabo ML, Rodriguez-Herrera JJ. Antimicrobial activity of essential oils against Staphylococcus aureus biofilms. Food Sci Technol Int. 2015;21(8):559-570. doi: 10.1177/1082013214553996

31. Carlson RP, Taffs R, Davison WM, Stewart PS. Antibiofilm properties of chitosan-coated surfaces. J Biomater Sci Polym Ed. 2008;19(8):1035-1046. doi: 10.1163/156856208784909372 